\title{
Diminishing Prospects for Young People: A Comparison of the Intergenerational Fairness Index and Generational Divide Index in Addressing the Problem
}

\author{
Luciano Monti ${ }^{1}$ \\ ${ }^{1}$ Fondazione Bruno Visentini, Rome, Italy \\ Correspondence: Luciano Monti, Fondazione Bruno Visentini, Via di Villa Emiliani 14/16, 00197 Rome, Italy. \\ E-mail: lmonti@luiss.it
}

Received: October 30, 2017

Accepted: November 8, 2017

Online Published: November 24, 2017

doi:10.5539/res.v9n4p160

URL: http://doi.org/10.5539/res.v9n4p160

\begin{abstract}
This paper focuses on the origins of the generational divide, namely, the unsustainability of national policies that have disproportionately benefitted the older generations to the detriment of younger generations. Much of southern Europe remains mired by unacceptably high rates of youth unemployment, which leaves an indelible scar on young people, poses economic problems for future generations, and threatens the European economies competitiveness. This paper outlines and compares the objectives, methodologies and results of two cutting-edge approaches in identifying the extent of these generational imbalances, namely: the Intergenerational Foundation's Intergeneration Fairness Index (IFI) and the Bruno Visentini Foundation's Generational Divide Index (GDI). The findings outline the differing objectives and methodologies of these respective approaches. Although both instruments arrive at broadly similar conclusions, (i.e. young people's diminishing prospects over time) there are palpable differences in the results. This is attributable to IFI and GDI's different aims and objectives: IFI is mainly helpful for country comparisons and GDI for fixing country-specific targets.
\end{abstract}

Keywords: generational divide, intergenerational fairness, generational gap, Neet, young people

\section{Introduction}

It is challenging to estimate the impact and measure the intensity of unsustainable growth of young generations (United Nations, 2013), since the recent recession is the product of many factors. Among the endogenous factors, we should consider mainly lower job protections and a less job-specific experience (Gorlich, Stepanok, Al-Hussami, 2013). Among the exogenous factors, there was the economic downturn, mainly in Europe. From a macroeconomic point of view, the gravity center displacement of big flows of the global economy to some geographic areas (such as China and other Asian countries) is one of the main causes for the geopolitical decline of Europe. Another cause was some of the policies of European integration, which have contributed to the current economic imbalances in Europe, most notably with the creation of the single market, first, and the ongoing European monetary union, second. For example, if we consider the sectors with the highest presence of young workers such as Retail, Manufacturing and Construction in 2008 (Eurofound, 2012a), we find that these sectors were the most affected by the economic downturn, particularly the Construction and Manufacturing industry. According to Eurostat data, from 2008 to 2011, the youth employment rate in Construction decreased by 27\%; and in Manufacturing by 25\% in the EU27. (Eurofound, 2012a). Nevertheless, other indicators can lead to some reflections on the intergenerational gap intensity. Elements to take into consideration to assess the intensity are mainly linked to three areas: i) economic stability ii) number of NEETs (Young People Not in Employment, Education or Training); and iii) youth unemployment rate.

Regarding the first area, researchers of the Canadian Centre for the Study of Living Standard (Osberg and Sharpe, 2011) provided a good starting point, measuring various indicators that would contribute together to ascertain the economic stability of a generation. These include the Economic Equality Index, which takes into account the GINI coefficient for $25 \%$, and the poverty rate for $75 \%$. This index shows how, over a period of thirty years, from 1980 to 2009, most European countries, apart from France and Sweden, recorded declining equality rates. In contrast, the safety index of poverty risk in old age fell, albeit slightly, in many countries, while the Economic Security Index (taking into account four indicators: unemployment risk, financial risks for disease and medical costs, the risk of 
poverty of single parent families and the risk of poverty in old age) underwent an overall decline. As previously mentioned, the safety rate is not the only index that decreased. The overall wealth rate also follows this trend. In fact, during the observed period in all the surveyed countries, the GDP per capita growth rate and the Index of Economic Well-Being (IEWB) growth rate did not always proceed at the same pace. The latter was always lower than the first, by almost one percentage point (Osberg and Sharpe, 2011).

Regarding the second point, a report by Eurofound (Eurofound, 2012a) which analyzes Eurostat data, highlights the increase of NEETs in Europe since the crisis began. In fact, in 2008, the percentage of NEETs between 15 and 24 years old stood at $11 \%$, while those between 25 and 29 years old, equaled $17 \%$. These percentages increased in 2011 to $13 \%$ and $20 \%$ respectively, amounting to 14 million individuals. The highest growth rate in NEETs were registered in Spain, Italy, Ireland and Bulgaria. According to the latest Eurostat data in 2015, the percentage of NEETs between 15 and 24 years old stood at $12 \%$ - a modest but encouraging decrease in comparison with the figures for 2014 (12.5\%) and 2013 (13\%) (Eurofound, 2016).

Finally, regarding the third aspect, it is clear how the recent crisis damaged younger workers much more than other age groups (Kingman and Seager, 2014). The IF survey by Kingman et al, reveals that after 2007, all age groups witnessed a fall in real wages, but a larger impact was felt by younger workers, particularly the cohort of 18-21year olds. In fact, from 1997 to 2013, 18-21year olds saw their gross weekly pay fall 19.05\% in real terms, whereas all older age groups saw real term increases.

\section{Method}

It is important to distinguish semantically three terms that have been utilized to describe cross-generational differences in very different contexts: "generational gap", "intergenerational fairness", and "generational divide." The semantics of these terms have been conflated despite engendering different meanings. "Generational gap" is concerned with the difference of opinions between one generation and another in respect of their values, politics and general beliefs. In today's usage, the reference "generational gap" habitually refers to a perceived gap between young people and their parents or grandparents. This term is unrelated to the research into the generational divide or intergenerational fairness. Moreover, although intergenerational fairness and generational divide are closely related, there are fundamental differences between these two concepts. This paragraph aims to underline these differences.

However, methodological aspects should initially be considered. The multi-dimensional approach for the identification of well-being indicators already considers empirical experimentations, both in the economic, social and environmental fields (Monti 2017). Moreover, the affirmation of sustainability growth models has also introduced new economic aspects, (i.e. the hidden and shadow prices mentioned above) that before, were not even taken into consideration. These early attempts, however, still present two weak elements, one theoretical and the other empirical.

The theoretical problem is that the surveys aggregation level normally does not consider different categories of population, neither in terms of age, nor in terms of status. Territorial perspective alone is not capable of highlighting what is called inclusive growth, since it does not comprise social exclusion enclaves and generational divide, which can be generated where standards of living are higher and where the labour market is very selective. Moreover, as already pointed out (Fitoussi 2013; Monti 2017) a multidimensional approach, if excessively amplified, has a negative impact on data interpretation for researchers, policy makers and citizens. Some of the sources used to apply the Intergenerational Fairness Index, for instance, are not available in all countries, so it is hard to make a comparison. However, these initial steps have been seminal in measuring the generational divide, the strong depletion of human capital, the scarring effects of youth unemployment (Gorlich, Stepanok, Al-Hussami, 2013) and the available stock of real productive assets (the so called generational accounting) (Osberg, 1997).

As I have recently pointed out (Monti 2017), the first pioneering attempt to measure the specific intergenerational fairness in the Intergenerational Fairness Index, was developed in UK, by The Intergenerational Foundation (Leach and Hanton, 2014, Hanton 2016). The adopted taxonomy is composed of nine domains: Unemployment, Housing, Pensions, Government debt, Participation in Democracy, Health, Income, Environmental Impact and Education. IFI has adopted 17 indicators, which is the same number as IFI in 2015, however, there have been some revisions to their taxonomy. In the most recent IFI of 2016, the housing costs indicator has been removed, one pensions indicator has been added to reflect the importance of pension saving to young peoples' long-term quality of live, and seven other indicators have been modified (Hanton, A 2016).

Some of the IFI indicators compare younger persons with the UK average, whilst other indicators deal with future generations. This first pursuit reveals a consistent deterioration in "intergenerational fairness" and a worsening of indicators from the year 2000, with the only exception of environmental impact in 2008 (mainly due to the 
reduction in energy production during the crisis), and participation in Higher Education.

According to the Intergenerational Foundation (IF), "the period since 2010 has also seen a sharp increase in intergenerational unfairness in spite of the pause in the Index's rise between 2012 and 2013 in UK. Driving the increase are rising levels of government debt, increasing house prices and low levels of house building. Also contributing to the rise of the Index are higher costs for state and unfunded public sector pensions, and a significant decline in the proportion of young people who are choosing to vote in elections. While improvements are occurring through falling costs for graduates in Higher Education with the impact of the higher threshold for loan repayments as well as higher GCSE pass rates and increased participation in higher education, these improvements are insufficient to counterbalance forces driving the Index higher."

As the name implies, GDI focuses on the generational divide, which in essence is about measuring the extent of delay that young people face in obtaining full autonomy and independence to pursue life's pursuits compared to the older generations (i.e. buying a house, borrowing money, pursuing higher education, suitable employment). For instance, it is well documented that it takes longer today for young people to access the "housing ladder" than previous generations. There are also impediments for some young people that are so insurmountable (such as child poverty and social exclusion) that life pursuits are inaccessible or even worse, indefinitely unobtainable. To illustrate the problem, imagine a running track containing life's pursuits, such as going to school, then university, finding a suitable job, obtaining a mortgage to buy a house and so forth. You are on the running track, but there are hurdles of varying heights, some are easily jumpable (i.e. going to high school) while other hurdles are too high to jump over (i.e. social exclusion). In short, GDI aims to measure the extent of this "generational divide," or put another way, the "delay" that young people face in reaching full-autonomy. The different methodologies employed reflect the different overriding objectives of IFI and GDI.

The temporal scope of the GDI data set ranges from 2004-2015 with provisional results estimated up to 2030. The results from GDI indicate that the young-old divide has widened consistently since 2007, and is forecast to deteriorate further beyond 2020. In particular, Housing, Income \& Wealth and Pensions have had the greatest impact in increasing the generational divide (See Monti, 2017 for more on GDI) (Marchetti F. Monti L.2017).

Naturally, the methodology between Intergenerational Fairness Index (IFI) and Generational divide index (GDI) differs. If the methods of IFI and GDI mirrored each other, our research would be of limited (or no) utility, reduced merely to a verifiable instrument. Instead, GDI differs in its scope and detail. To remind the reader, the IFI adopts 9 domains and 17 indicators (Unemployment, Housing, Pensions, Government debt, Democracy, Health, Income, Environment and Education). The Bruno Visentini Foundation (BVF) has built on these nascent first attempts by formulating its very own index, named Generational Divide Index (Monti 2017).

GDI is composed of 14 domains and more than 40 indicators for the revised Index (12 domains and 27 indicators for original Index: see Monti, 2017). They are Unemployment, Housing, Pensions, Government Debt, Participation in Democracy, Health, Income \& Wealth, Environment, Education \& Culture, Access to Credit, Mobility, Legality, Innovation and Gender Equality GDI therefore consists in a greater number of categories and indicators (for comparison, see Appendix 1).

However, IFI is particularly useful from the standpoint of providing a comparative model between different European countries. I hasten to add that there is no right or wrong approach and both methodologies have their respective merits. In short, both GDI and IFI target the same end, but through slightly different means. Unsurprisingly, given the differing methodological approaches, the results also show notable differences.

\section{Results}

In order to carry out an apposite comparison between the IFI and GDI results, the Bruno Visentini Foundation extracted the IFI's European data from 2004, and normalized the figures to an index of 100 to correspond with GDI data series. The reasoning is as follows: IFI's European index is formulated by using the EU median IFI trend as the base index figure (i.e. 100) and each individual country's index is calibrated in relation to the EU average accordingly. So, for example, the data series for Italy in 2005 starts at the index number 125.2, which signifies that Italy as a worse IFI vis-à-vis the EU average (which is 2005 starts at index number 100).

The GDI indicators also aim to explore deeper into local, regional differences within the selected sample, Italy. The reasoning is as follows: it is well documented that there are gross inequalities between the comparatively affluent North of Italy (from the region of Lazio and beyond) and the poorer Southern regions (regions from Campania and beyond). Therefore, GDI has decided to provide an index that measures not only the national aggregate level of GDI but also intra-country GDI levels. In addition, GDI will measure the differences that pertain between the genders. For example, GDI will measure the unemployment rate for young men and young women. The reasoning 
for this approach is as follows: gender differences are a burden for the whole population; not only the gender most disproportionally affected. If, for example, it is expected that GDI is worse for young women vis-à-vis young men, this has pernicious consequences for the whole country.

The 2016 Intergenerational Fairness Index (see figure 1 below) tells of the continuing decline in young people's life chances compared to previous generations. This deterioration is attributed to inter-alia rising pension liabilities per worker, healthcare costs have increased due to an aging demographics, disproportionately high youth unemployment rates vis-à-vis the wider population, increasing government debt per person, and rising housing costs. Most alarming is the cost of public sector occupational pensions' unfunded liabilities per person in the workforce, and the level of government debt per worker, which have risen exponentially since the dawn of the 2008 crisis. (Hanton, 2016)

The Generational Divide Index arrives at similar conclusions, namely the prospects for young people have deteriorated. However, GDI applied to Italy identifies an even greater deterioration for young people than IFI. From 2007 onwards, the young-old "divide" has widened (see Figure 1 below). The forecasts estimate the divide to widen further beyond 2020. There has been a notable widening of the divide in Income\& Wealth, Housing and Pensions (see Figures 2-4 below). Regarding the former, rising labour taxes, a more flexible, but equally insecure labour market and introduction of a dual labour market has contributed to a deteriorating picture for incomes of young people. In respect of housing, young people's disposable incomes have fallen faster than house prices, rendering houses unaffordable for many young people. The much-publicised "Credit Crunch" resulting from the 2008 Financial Crisis, has adversely affected young people, disproportionately compared to older generations, making it harder to borrow money from banks for a mortgage. Furthermore, rising energy bills and housing expenditure in recent years have imposed further financial stresses on young people. Regarding pensions, state pension costs have risen consistently since the early 1990s. The changing demographical dynamics i.e. of fewer working people and an aging population has resulted in increasing state liabilities.

\section{Fig.1 - GDI and IFI comparison: Italian results}

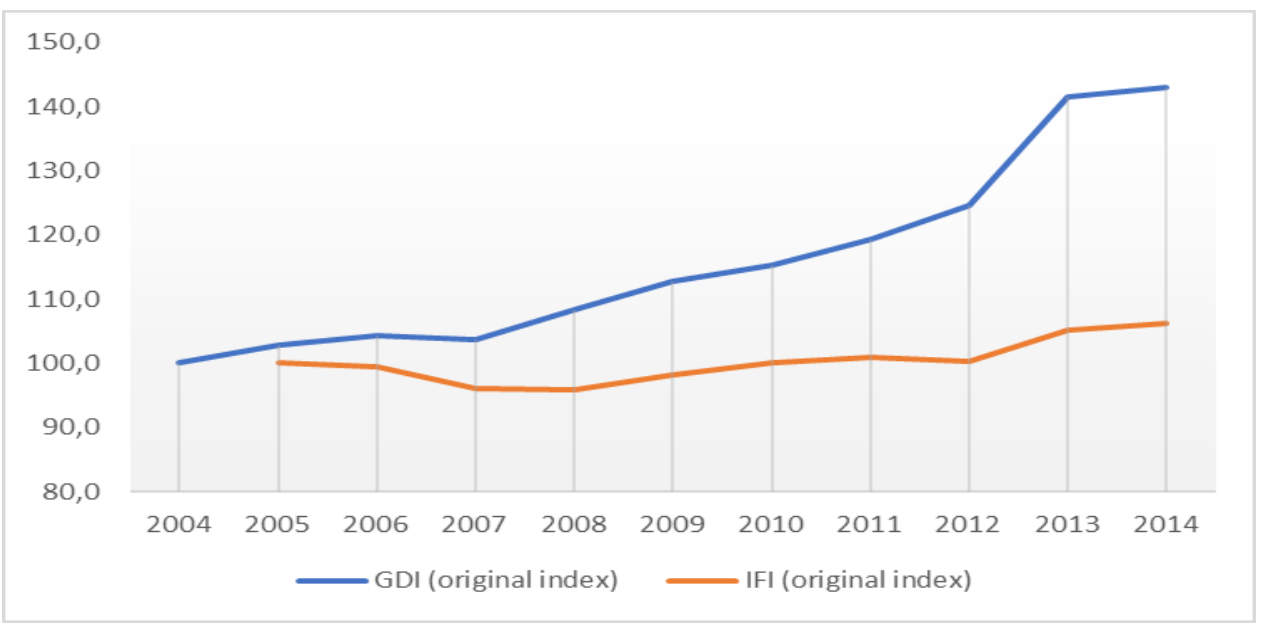

As shown in the graph above, similar conclusions can be deduced from both GDI and IFI, namely: the "generational divide" or "generational fairness" has deteriorated further in recent years. However, there are marked discrepancies in the results of IFI and GDI that are of deep interest to researchers. Three indicators revealed palable differences, particular in the fields of Income, Pensions, and Housing. IFI revealed that the income fairness has only slightly worsened. However, the GDI income indicator represents a dramatic deterioration in the generational divide, from 100 to over 250 index points in the space of 8 years (2005-2013).

The marked discrepancy in Income indicators (see Figure 2) is attributed to the different set of indicators used. As you can see from Fig.1 above, IFI focussed on income only. Conversely, GDI has expanded the remit to include family wealth. GDI's ratio between young people's average earnings and average earnings of the total population reveals a fairly flat and constant trend, similar to that of IFI. However, when family wealth in taken into account, GDI's income and family wealth indicator shows a marked deterioration. 
Fig. 2 Income \& Family Wealth GDI\&IFI Index comparison: Italian results

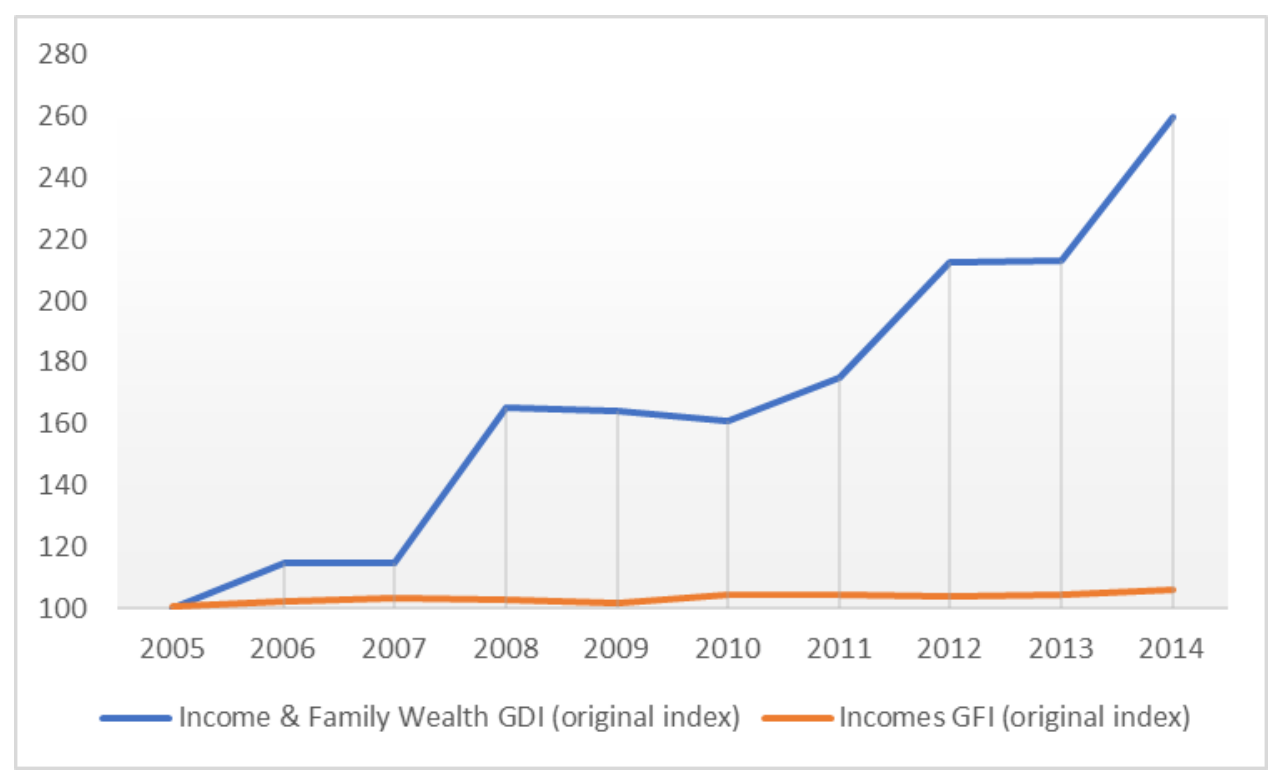

There are also discernible differences in the results for the Pensions Index (see figure 3). This is likely a result of a new IFI indicator that the GDI has not adopted, namely the "proportion of young workers who aren't contributing to a pension scheme." (see Hanton, A 2016) The Bruno Visentini Foundation has decided not to consider this indicator because the state predominantly pays a young persons pension contributions (even more so, in light of the Italian Jobs Act of 2014). It was therefore not deemed a pertinent indicator for Italy's specific circumstances.

\section{Fig. 3 Pension Index GDI\&IFI comparison: Italian results}

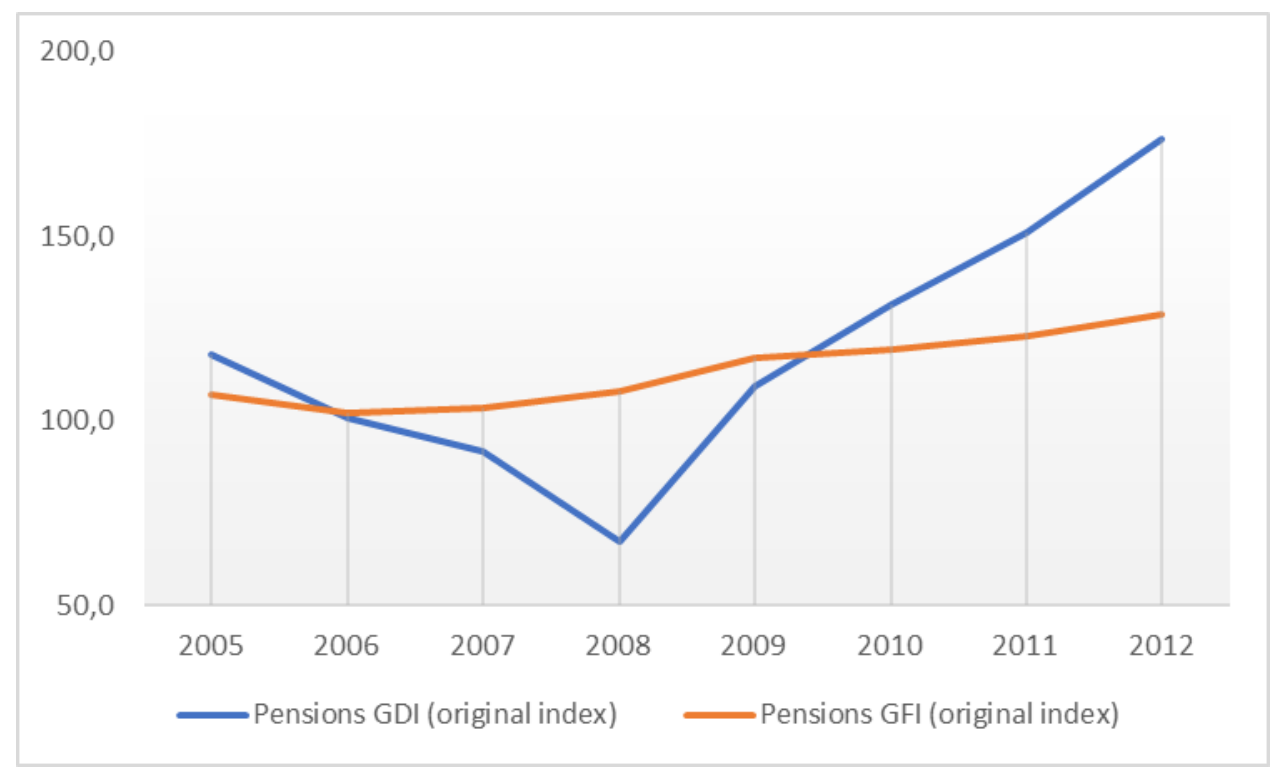

Lastly, the Housing indicator was another notable outlier (see figure 4). IFI recorded little or no worsening in conditions for young people, but GDI calculates a modest fall of circa 20 index points since measurements were taken in 2004. All other indicators revealed broadly similar trends. This is attributable to IFI removing "Housing costs as \% of disposable income", which was an indicator that GDI retained. 


\section{Fig. 4 Housing costs Index GDI\&IFI comparison: Italian results}

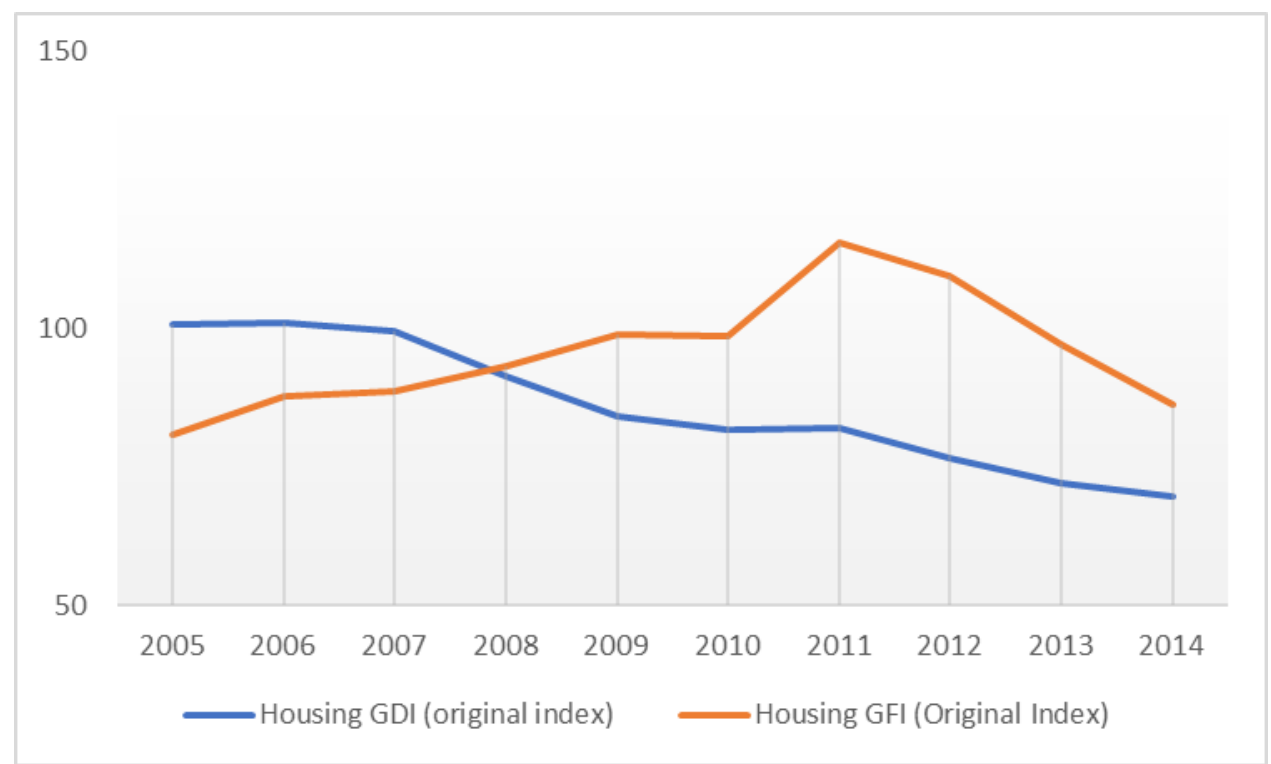

\section{Conclusion}

It is important to distinguish "generational gap" from "intergenerational fairness" and "generational divide." "Generational gap" is concerned with the difference of opinions between one generation and another in respect of their values, politics and general beliefs. In today's usage, the reference generational gap habitually refers to a perceived gap between young people and their parents or grandparents. This term is unrelated to the research into the generational divide or intergenerational fairness. Moreover, although intergenerational fairness and generational divide are closely related, there are fundamental differences between these two concepts. The former aims to measure the disparities in intergenerational fairness and some of the indicators are the result of a ratio between different age cohorts. On the other hand, GDI makes use of both ratios between age cohorts and indicators, measuring barriers to youth sustainable growth. IF is concerned with the norms of global justice, sustainable growth and regulations, and the promotion of fairness and equality between different generations. IF also endeavors to provide a comparative study between countries but risks underestimating (see Income in figure 2) or overestimating (see Housing Costs in figure 4) some specific key factors of generational divide. The key difference is IFI provides a comparative model between young and old generations, whereas GDI's target cohort is a single generation (i.e. young people), which aims to measure the life obstacles that young people face today.

Conversely, the objective of GDI is to provide an analysis of a single country, because each country has a specificity. For example, IF measures the level of student debt which is pertinent for the UK, but insignificant for Italy. GDI measures the legality divide for Italy, which is highly relevant to that country but largely irrelevant to the UK. In short, GDI represents an index model tailored to the specific circumstances of a specific country. GDI's overarching objective is governance: namely to influence policy-making to improve the life chances of young people.

\section{Acknowledgements}

The proof reading, figures and Appendix 1 are provided by Jan Erik Kermer. Contribution to the publication expenses has been provided by Fondazione Bruno Visentini.

\section{References}

Bengtson, V. L., \& Oyama, P. S. (2007). Intergenerational solidarity: Strengthening Economic and Social Ties. New York: United Nations Headquarters.

Eurofound (2014). Mapping youth transitions in Europe, Publications Office of the European Union, Luxembourg.

Eurofound (2016). Exploring the diversity of NEETs, Publications Office of the European Union, Luxembourg.

Eurofound (2012). NEETs - Young people not in employment, education or training: Characteristics, costs and 
policy responses in Europe. Luxembourg: Publications Office of the European Union.

Eurofound (2009). Young people and NEETs in Europe; First Findings. Luxembourg.

European Commission (2009). Intergenerational solidarity: Analytical report. Flash Eurobarometer 269. The Gallup Organisation.

European Commission (2012). White Paper: An Agenda for Adequate, Safe and Sustainable Pensions, COM (2012) 55 final. Brussels.

Finnish Ministry of Employment and the Economy (2013). Youth Guarantee.

Fitoussi, J. P. (2013). Le Théorème du lampadaire. Paris, Les liens qui libèrent.

Gorlich, D, Stepanok, I., \& Al-Hussami, F. (2013). Youth Unemployment in Europe and the World: Cause, Consequences and Solutions. Kiel Policy Brief 59.

Hanton, A. (2016). The IF Intergenerational Fairness Index: 2016 Edition. London: The Intergenerational Foundation

International Labour Organization (2012). Eurozone job crisis: trends and policy responses. Studies on growth with Equity. Geneva.

Kingman, D., \& Seager, A. (2014). Squeezed Youth: The Intergenerational Pay Gap and the Cost of Living Crisis. London: Intergenerational Foundation.

Kliesen, K. L. (1997) Assessing the Generational Gap in Future Living Standards through Generational Accounting. The Regional Economist.

Leach, J., \& Hanton, A. (2014) The IF Intergenerational Fairness Index: 2014 Edition. London: The Intergenerational Foundation.

Marchetti, F., \& Monti, L. (2013). "Primi fondamenti e strumenti di politica economica intergenerazionale". Amministrazione In Cammino, p. 1-12

Monti, L. (2013). Teoria e principi di politica economica intergenerazionale. Roma: Luiss University Press.

Monti, L. (2016). Ladri di Futuro, La rivolta dei giovani contro l'economia ingiusta. Roma: LUISS University Press.

Monti, L. (2017). Generational Divide: A New Model to Measure and Prevent Youth Social and Economic Discrimination Review of European Studies; Vol. 9, No. 3

OECD (2006). Employment Outlook.

OECD (2011). Paying for the Past, Providing for the Future: Intergenerational Solidarity.

Osberg, L. (1997). Meaning and Measurement in Intergenerational Equity.

Osberg, L., \& Sharpe, A. (2011). Moving from a GDP-based to a Well-being based metric of economic performance and social progress: results from the index of economic well-being for OECD countries, 1980-2009, Centre for the Study of Living Standard Research Report 2011. Ottawa: CSLS.

Policy Brief July 2010. European Centre.

Rosenbaum, P. R., \& Rubin, D. B. (1983). The central role of the propensity score in observational studies for causal effects. Biometrika 70(1), 41-55.

Sabbati, G. (2014). Ageing population: projections 2010 - 2060 for the EU28

Stiglitz, J. E., Sen A., \& Fitoussi, J. P. (2009). Report by the commission on the measurement of economic performance on social progress. Paris.

United, Nations. (2013). Intergenerational solidarity and the needs of future generations. Report of the Secretary-General. 
Appendix A: The comparison between 2016 revised IFI and 2017 Revising GDI

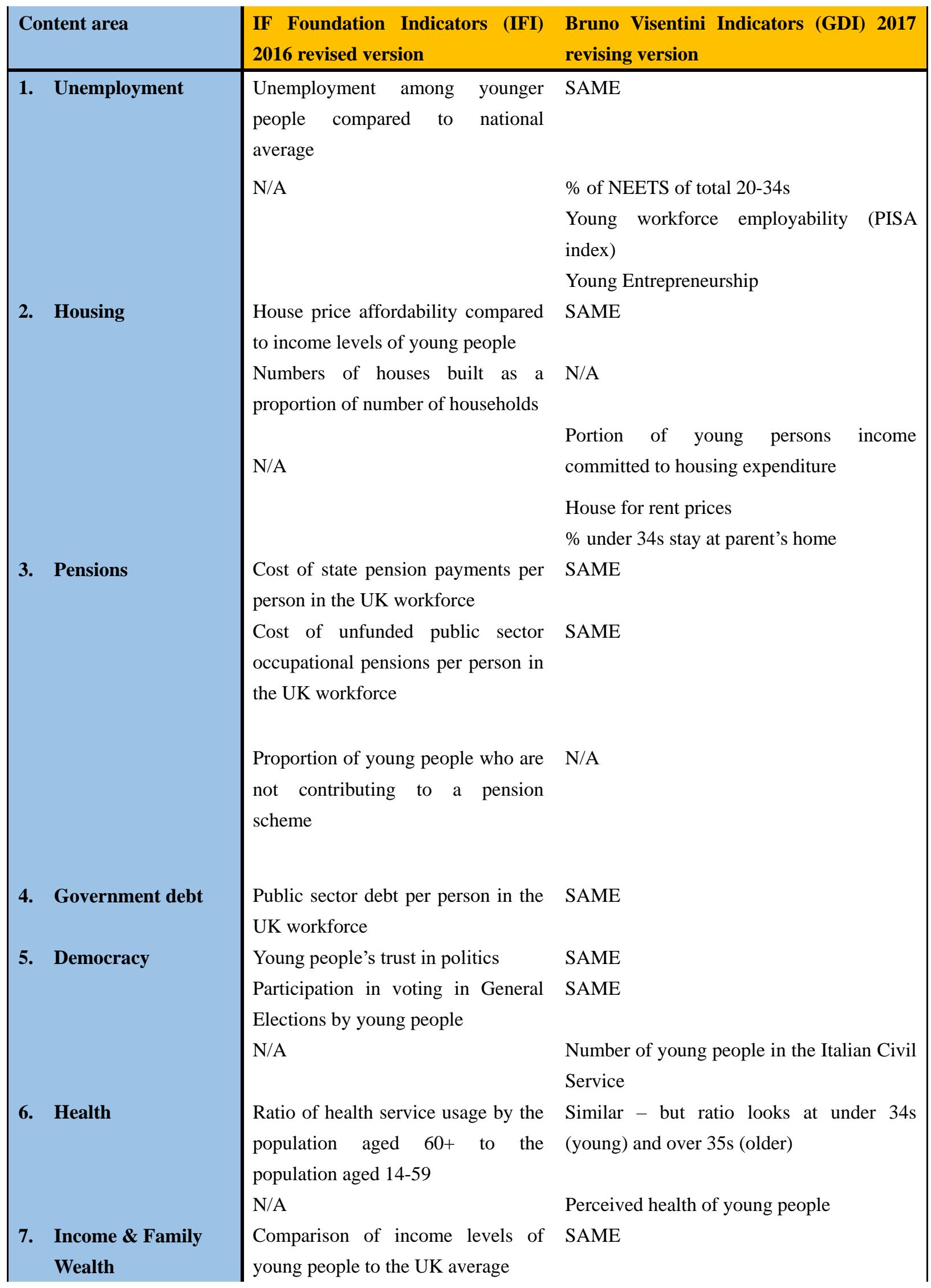




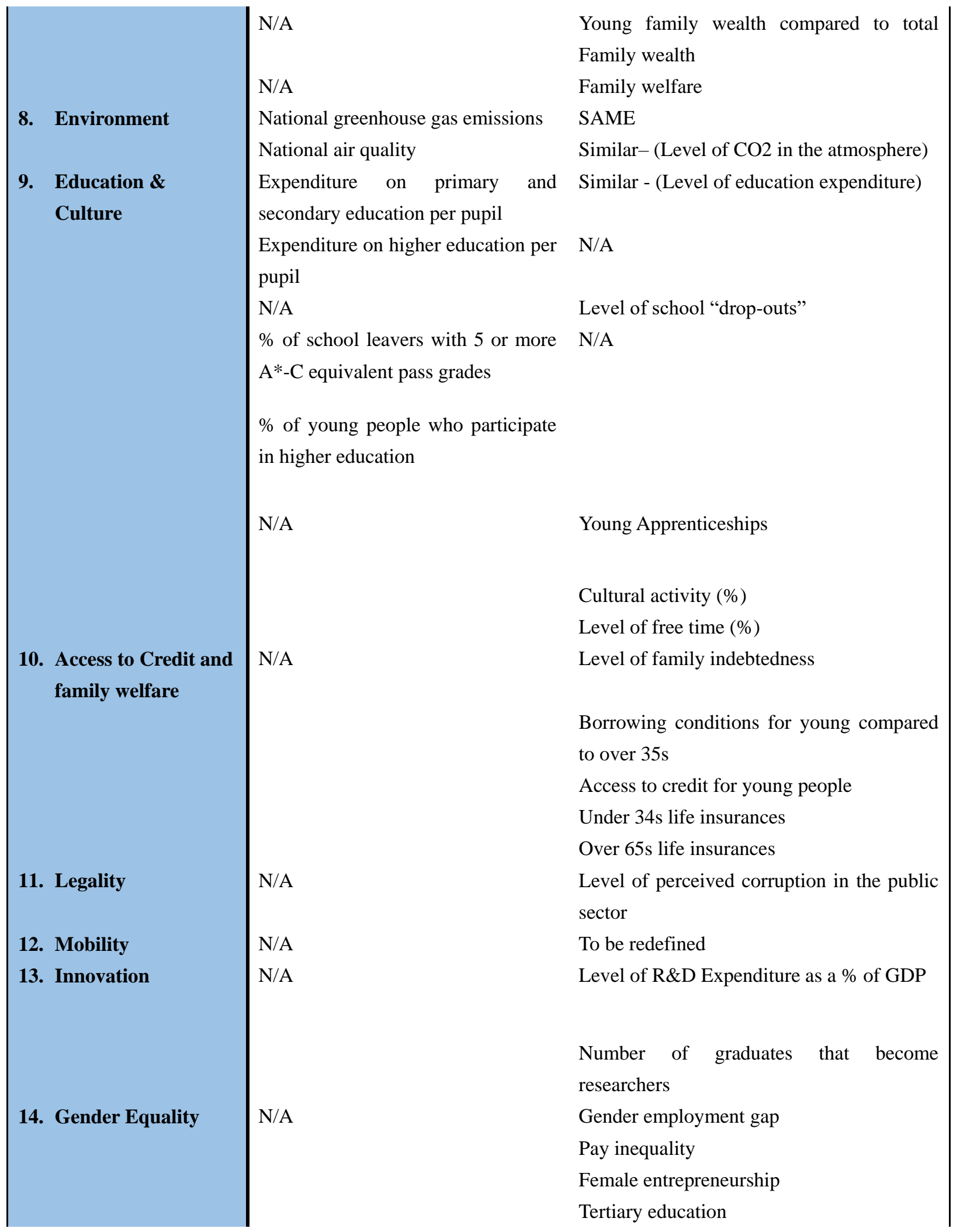




\section{Copyrights}

Copyright for this article is retained by the author(s), with first publication rights granted to the journal.

This is an open-access article distributed under the terms and conditions of the Creative Commons Attribution license (http://creativecommons.org/licenses/by/4.0/). 